\title{
Propose a New Quality Model for M-Learning Application in Light of COVID-19
}

\author{
Ahmad Althunibat $\mathbb{D D}^{1}{ }^{1}$ Feras Altarawneh, ${ }^{1}$ Raneem Dawood, ${ }^{1}$ \\ and Mohammed Amin Almaiah (iD) ${ }^{2}$ \\ ${ }^{1}$ Department of Software Engineering, Faculty of Science and Information Technology, Al-Zaytoonah University of Jordan, \\ Amman, Jordan \\ ${ }^{2}$ College of Computer Science and Information Technology, Department of Computer Networks and Communications, \\ King Faisal University, Al-Ahsa, Al Hofuf 31982, Saudi Arabia
}

Correspondence should be addressed to Ahmad Althunibat; a.thunibat@zuj.edu.jo

Received 10 October 2021; Accepted 18 January 2022; Published 1 March 2022

Academic Editor: César A. Collazos

Copyright (c) 2022 Ahmad Althunibat et al. This is an open access article distributed under the Creative Commons Attribution License, which permits unrestricted use, distribution, and reproduction in any medium, provided the original work is properly cited.

\begin{abstract}
The coronavirus disease (COVID-19) prevented millions of students around the world from receiving their lessons, because of the closure of thousands of schools. The new COVID-19 global epidemic invaded the barriers of time and space. Using mobile phones in education is a new form of the distance learning system. M-learning is characterized by many characteristics, the most important of which are providing an interactive educational environment, flexibility in space and time, better adaptation to individual needs, acquisition of knowledge, interactive effectiveness, and developing self-learning skills for students. The main aim of this paper is to suggest a quality model for M-learning applications for children which contains the most common characteristics of M-learning, which must be taken into account when designing M-learning applications. Through previous studies related to the quality model for M-learning applications, we proposed two quality characteristics, technical and pedagogical. We proposed 8 subcharacteristics with their features following the structure of the IOS/IEC 912 and DeLone and McLean IS model to find the effect of technical and pedagogical factors on user satisfaction with M-learning applications for children. Results show that the proposed model can be useful and effective to ensure the development of high-quality M-learning applications.
\end{abstract}

\section{Introduction}

The COVID-19 crisis resulted in millions of students around the world being cut off from receiving their lessons, due to the closure of thousands of schools. Schools were closed as a result of the measures taken by the authorities to reduce the spread of COVID-19. Therefore, numerous educational foundations in Arab nations have turned to the choice of distance learning because the educational program should keep closing any instructive hole that may result from the emergency. Similarly, as the new corona pandemic, the virus attacked the boundaries, and the "distance learning" that went with the spread of the infection came to clear the hindrances of existence.
E-learning is characterized as an educational and instructive framework offering educational and preparing/ instructive programs to undergraduates without restrictions of having space or time, using communication techniques and various technologies from the Internet, computers, smartphones, direct broadcast through electronic applications, and other technologies [1,2]. Using mobile phones in learning is a new form of distance learning system [1]. There is a strong trend to use mobile learning (M-learning) in learning processes because one of its effects is to increase the motivation of the children to learn and improve communication with them through what they use from devices and technological applications, which may be reflected in improving their skills. Many decisions emphasized the 
importance of using M-learning in educational processes $[3,4]$. M-learning is characterized by many characteristics, the most important of which are providing an interactive learning environment, flexibility in space and time, better adaptation to individual needs, acquisition of knowledge, interactive effectiveness, developing self-learning skills for students, and the ability to communicate knowledge through various audio-visual media or reading [3].

Considering this knowledge explosion and the development of information and science, it is not at this point adequate to leave the teaching and properly shift to another level of education. It was necessary to prepare randomly in advance considering a clear philosophy that leads to the educational process and learning strategies for the children according to their capabilities and development requirements in a cultural environment and specific circumstances [3]. There are many good applications that children can learn but have no real learning goals because they do not follow quality models. So, parents need to note that just because an app is not in the "Education" section of digital stores, it does not mean it is non educational [5]. Most relevant studies that have addressed this problem provide few M-learning features such as usability, control, and flexibility while ignoring some important characteristics such as pedagogy, technology, and user satisfaction [5]. Although there were some critical interests in M-learning, people still neglect its advantages that we can have in the future through M-learning networks [6]. In this manner, as of late, an increment has been seen in the number of exact examinations planned to analyze the elements influencing M-learning acknowledgment and reception and the advantages colleges get from M-learning [7-10], while few have paid attention to examining the effect of quality factors on M-learning usage. These studies ignore the fact that quality factors serve as important roles for meeting students' perceptions and ensuring the successful development of M-learning applications, and, therefore, it is important for examining such factors.

Papadakis et al. [5] proposed quality model that will provide the developers with a guideline to building successful and effective children's mobile learning applications. The proposed model in this study will provide a base for building the children's mobile learning applications that meet these requirements by providing important characteristics such as pedagogy, technology, and user satisfaction.

Therefore, this study contributes to enriching the field of research in mobile learning applications especially in learning for children through proposing a new quality model that includes new important quality characteristics, analyzing the related previous studies, and the findings of the empirical study (questionnaire). Therefore, this finding may open the way for other researchers, especially those interested in children's mobile learning applications.

This paper aims to investigate previous studies related to the model of quality M-learning application for children. A quality model for M-learning application for children is suggested, which contains the most common characteristics of M-learning that must be taken into account in the design of learning for mobile applications. The validity of the proposed quality model is verified using the quantitative method to set the M-learning application. The development of the M-learning model depends on the proposed model.

\section{Theoretical Background}

In this section, we briefly present the concepts related to e-learning, mobile learning, and M-learning quality.

2.1. E-Learning. E-learning is one innovation of educational technology and one form of distance education that depends on the use of computers and the use of the Internet and the technology associated with it in building and developing educational resources, with less time and effort, and the greatest benefit, anytime, anywhere, and most of the time; E-learning is in an environment away from the teacher, which provided more opportunity for more education to be received with ease [1]. E-learning is among the educational and technical methods available to everyone as it provides the students or the users with information and supports it with pictures, sounds, and graphics and also provides electronic libraries with high-quality technologies and other advantages. They consider the learner according to his educational ability and following his previous experiences. From this standpoint, we can say that E-learning is a way to transform class education into education with the help of technology [1].

2.2. Mobile Learning. Previous studies viewed the benefits derived from the M-learning system from the university students' perspective. For example, one main benefit of using an M-learning system is an increment like educating and learning, just as an improvement in the cooperation among understudies and teachers [8]. Moreover, M-learning systems help educational institutions increase student enrollment, enhance their reputation, respond quickly to change, and lower costs [8].

Mobile learning, otherwise called M-learning, is another approach to get to M-learning content. M-learning upholds continuous access to the learning process $[11,12]$. It is based on wireless communications. So, the learner can access educational materials and seminars anytime and anywhere, and $\mathrm{M}$-learning also refers to the use of mobile devices in the teaching and learning process, as it focuses on using the techniques available in wireless communication devices to communicate information outside the classroom. It should be possible to utilize gadgets and devices, for example, telephone, PC, or tablet [11]. You can adapt to any place and at whatever point you need [3].

2.3. M-Learning and Quality. The concept of quality in this study reflects a degree of excellence of learning content quality and learning service quality of the M-learning system. Because of increasing sophistication and, with it, challenges in the information systems field, higher education institutions are eager to enhance the quality of their systems as a means of maximizing their potential for growth [7]. The importance of quality factors has been widely examined in 
prior research in several fields such as e-learning quality [13], learning management system quality [14], and M-learning quality [5]. It is a set of specifications required in M-learning environments to ensure its success and the quality of its design and development, so it becomes a tool to guide the production of M-learning systems and maintain their continuity; M-learning environment standards become exemplary performance measures, evaluation criteria, and guidelines for developments and improvements and a tool that helps in decision in the sense of a set of conditions required in M-learning environments to ensure the quality of their design [12, 14-16]. Providing quality in M-learning is a very important problem for any program or academic course. If quality is a prerequisite for the success of the educational process, quality becomes a necessary problem for M-learning in particular. The success of any educational system is highly dependent on its commitment to internationally agreed quality standards. The success of the portable learning system depends on the relevance of the outputs to goals considering their achievement of the approved quality standards [12]. Quality is nowadays a major issue in modern education especially for learning via mobile devices, where the application of quality can be a key factor in success [12].

According to the existing literature, in recent years, an increase has been observed in the number of empirical studies intended to examine the factors affecting acceptance, adoption, usage, and implementation of M-learning and the benefits universities derive from M-learning systems [6-9]. For example, Almaiah and Al Mulhem [4] proposed a new model to identify the most important factors that could motivate students to accept and use M-learning system. They identified 4 success factors of mobile learning, which were subdivided into the following categories: (i) innovative factors (security, protection, similarity, relatively favorable position, and trust), (ii) hierarchical components (protection from change and technological availability), (iii) social elements, and (iv) quality variables (nature of the framework, nature of substance, and nature of administration). Then, again, [6] inspected the impact of various components on M-learning applications improvement at three primary phases of utilization (static stage, association stage, and exchange stage).

The outcomes demonstrated that the main variables identified with the point of view of the user to think about when creating M-learning in three phases were framework similarity, security, data quality, awareness, seen practical advantage, self-viability, accessibility of assets, and trust [3]. Almaiah et al. [2] Led quantitative investigation with 275 undergrad Jordanian understudies at the college of Jordan and called attention to that trust, seen security, seen convenience, and seen handiness are fundamental variables for effective selection and usage of M-learning framework. Almaiah and Alismaiel [8] proposed a structure for M-learning acknowledgment dependent on integrating the Technology Acceptance Model (TAM) with the refreshed DeLone and McLean's model (DL\&ML). The examination intended to research the impact of value components and individual variables on student's fulfillment and expectation to the utilization of the M-learning network. The outcomes presumed that quality components identified with framework quality, data quality, and administration quality are fundamental measurements for guaranteeing understudies' fulfillment and goal to the utilization of the M-learning framework. Likewise, Almaiah et al. [9] proposed a halfbreed quality model for M-learning dependent on researches of DeLone and McLean data framework achievement model (DL\&ML) with the TAM model to look at the impact of 10 quality measurements on M-learning framework acknowledgment. They uncovered that the most basic components identified with incrementing the students acknowledgment were content plan quality, usefulness, UI configuration, learning content quality, openness, responsiveness, personalization, and intelligence. In another investigation, Almaiah et al. [9] created three structures for M-learning advancement dependent on quality variables got from the refreshed DeLone and McLean data framework achievement model.

Finally, a recent study conducted by Nizam Ismail et al. [6] investigated the important factors that affect students' acceptance of mobile learning. The study applied the Unified Theory of Acceptance and Use Technology (UTAUT) model and revealed that perceived data quality, similarity, trust, sense of awareness, and accessibility of assets, self-adequacy, and security are the principal sparks of understudies' acknowledgment of the M-learning framework and subsequently achievement of the execution of M-learning projects.

Based on Table 1, the majority of M-learning studies have considered students' perceptions for determining the factors that affect acceptance, adoption, and usage of mobile learning, while few studies have paid attention to users' perceptions of quality factors for M-learning applications. These studies ignore the fact that quality factors serve as important roles for meeting students' perceptions and ensuring the successful development of M-learning applications, and, therefore, they are important for examining such factors. The existing literature offers little insight into the quality factors of M-learning systems. There are a limited number of examples that look at this, including the studies by Almaiah et al. [9] and Qian et al. [10], which identified various M-learning quality factors in educational institutions. However, as far as we have been able to determine, few of these studies have empirically identified the important quality factors of M-learning applications development. Consequently, this study aims to propose and empirically examine a new model of the effect of quality factors on M-learning application development.

\section{The Research Models and Hypothesis}

There are a set of characteristics required in M-learning environments to ensure the quality of their design. Attention to quality standards has become a global movement, and it is a national demand in all areas, including education, so quality becomes a tool for guiding, producing, and maintaining portable learning systems [18]. There are many 
TABLE 1: Related work.

\begin{tabular}{|c|c|c|}
\hline Literature & Purpose of the study & Findings \\
\hline $\begin{array}{l}\text { Papadakis and } \\
\text { Kalogiannakis (2017) } \\
\text { [3] }\end{array}$ & $\begin{array}{l}\text { Conducted quantitative study with } 275 \text { undergraduate } \\
\text { Jordanian students at the University of Jordan to } \\
\text { explore the students' acceptance of mobile information } \\
\text { systems }\end{array}$ & $\begin{array}{l}\text { Pointed out that trust, perceived security, perceived ease } \\
\text { of use, and perceived usefulness are vital factors for } \\
\text { successful adoption and implementation of the M- } \\
\text { learning system }\end{array}$ \\
\hline $\begin{array}{l}\text { Almaiah and Mulhem } \\
\text { (2019) [4] }\end{array}$ & $\begin{array}{l}\text { Proposed a new model to identify the most important } \\
\text { factors that could motivate students to accept and use } \\
\text { the M-learning system }\end{array}$ & $\begin{array}{c}\text { They identified } 4 \text { success factors of mobile learning, } \\
\text { which were subdivided into the following categories: (i) } \\
\text { innovative factors (security, protection, similarity, } \\
\text { relatively favorable position, and trust), (ii) hierarchical } \\
\text { components (protection from change and technological } \\
\text { availability), (iii) social elements, and (iv) quality } \\
\text { variables }\end{array}$ \\
\hline $\begin{array}{l}\text { Nizam Ismail et al. } \\
(2020) \text { [6] }\end{array}$ & $\begin{array}{l}\text { Inspected the impact of various components on M- } \\
\text { learning applications improvement at three } \\
\text { fundamental phases of use (static stage, } \\
\text { communication stage, and exchange stage) }\end{array}$ & $\begin{array}{l}\text { The outcomes demonstrated that the main variables } \\
\text { identified with users' insights to contemplate when } \\
\text { creating M-learning in three phases were framework } \\
\text { similarity, security, data quality, mindfulness, seen } \\
\text { practical advantage, self-viability, accessibility of assets, } \\
\text { and perceived trust }\end{array}$ \\
\hline $\begin{array}{l}\text { Almaiah and Alismaiel } \\
(2019)[8]\end{array}$ & $\begin{array}{l}\text { Conducted quantitative study with } 275 \text { undergraduate } \\
\text { Jordanian students at the University of Jordan to } \\
\text { explore the students' acceptance of mobile information } \\
\text { systems. }\end{array}$ & $\begin{array}{l}\text { Pointed out that trust, perceived security, perceived ease } \\
\text { of use, and perceived usefulness are vital factors for } \\
\text { successful adoption and implementation of the M- } \\
\text { learning system. }\end{array}$ \\
\hline $\begin{array}{l}\text { Almaiah et al. (2016) } \\
\text { [9] }\end{array}$ & $\begin{array}{c}\text { Developed three systems for M-learning development } \\
\text { based on quality factors derived from the updated } \\
\text { DeLone and McLean information system success } \\
\text { model. }\end{array}$ & $\begin{array}{l}\text { They uncovered apparent data quality, perceived } \\
\text { similarity, trust, a level of awareness, accessibility of } \\
\text { assets, self-viability, and security, which are the primary } \\
\text { inspirations of student's acknowledgment of the M- } \\
\text { learning framework. }\end{array}$ \\
\hline $\begin{array}{l}\text { Alrasheedi and } \\
\text { Capretz (2020) [1] }\end{array}$ & $\begin{array}{l}\text { Proposed a hybrid quality model for M-learning based } \\
\text { on combining the updated DeLone and McLean } \\
\text { information system success model (DL\&ML) with } \\
\text { TAM model to examine the effect of } 10 \text { quality } \\
\text { dimensions on M-learning system acceptance. }\end{array}$ & $\begin{array}{l}\text { They revealed that the most critical factors relating to } \\
\text { increasing the students' acceptance were content design } \\
\text { quality, functionality, user-interface design, learning } \\
\text { content quality, accessibility, responsiveness, } \\
\text { personalization, and interactivity. }\end{array}$ \\
\hline
\end{tabular}

foundations for quality paradigms to consider while designing and developing portable learning environments based on M-learning technology [1]. We have come up with a list of criteria for designing M-learning environments with a focus on the most common and important characteristics of M-learning to consider. After reviewing several studies and research, the quality model for children's M-learning applications in this paper is based on ISO 9126, the most widespread quality standard [19]. Additionally, the IS success measurement is one of the first to care about the effectiveness of information systems, which focuses on the functional requirements of information systems [19]. The proposed model defines two main characteristics: technology and pedagogy, each of them includes subcharacteristics as shown in Figure 1 which depicted the research model.

3.1. Technology. Technology factor can be defind as the utilization of actual hardware, software, and instructive hypothetical to encourage learning and improving the education. In this manner, technical elements affect students' satisfaction of M-learning applications $[11,12,14-20]$. Therefore, the following hypothesis is formulated to test the effect of technical factors on user satisfaction.
Hypothesis 1: technical factors have a significant effect on user satisfaction with M-learning applications for children.

The M-learning technical characteristics comprise the following subcharacteristics:

Functionality: the M-learning function shows the ability of the application to provide a function that meets the explicit and implicit needs of users under specific conditions of use, meaning what the program does to meet the needs [14-16]. The application includes all the features needed to accomplish the required tasks and provide an improved educational experience [21].

Hypothesis 1a: functionality has a significant effect on user satisfaction with M-learning applications for children.

Performance: the achievement of M-learning applications relies upon the obligation to execution and improved proficiency $[12,14-21]$. Application reaction time execution should be adequately quick to meet the client's needs. Significant delay times can decrease revenue and weariness by students, bringing about reluctance to utilize these applications [12]. 


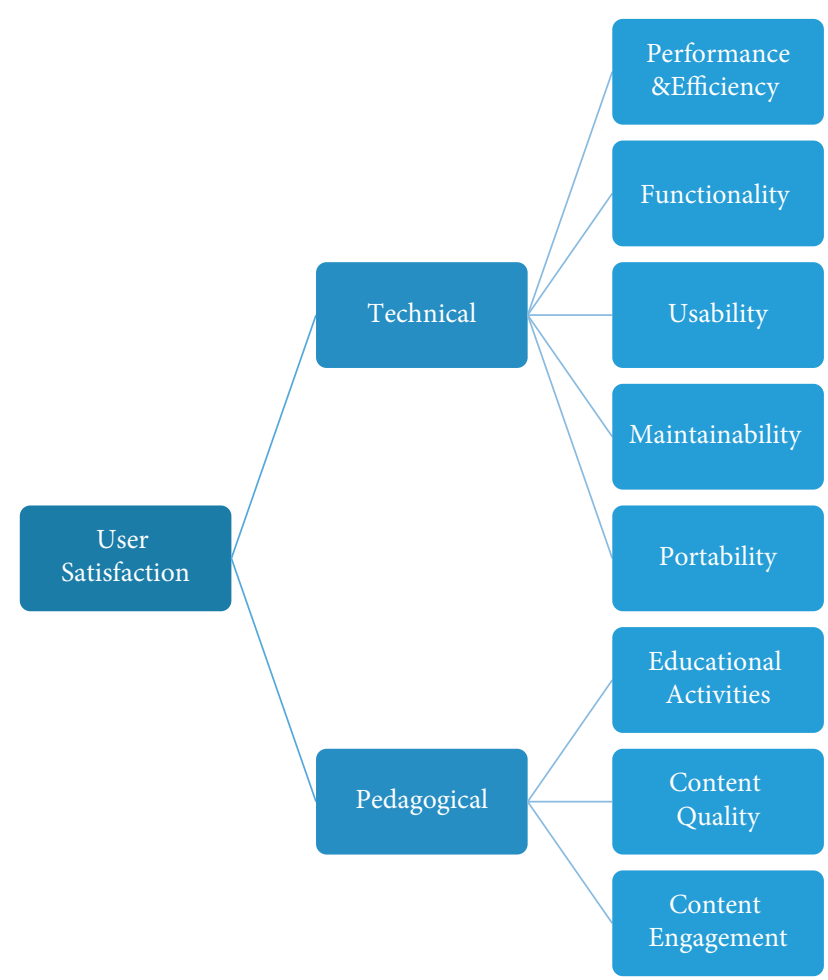

FIgURE 1: Quality model for M-learning application for children.

Hypothesis 1b: performance has a significant effect on user satisfaction with M-learning applications for children.

Usability: the ease of use in M-learning has been characterized as a subjective attribute that characterizes the best, productive, and good method of utilizing the UI [22]; it inspects the degree to which M-learning can accomplish explicit objectives in a powerful, proficient, and palatable way of use [21]. In learning conditions, particularly for cell phones, the interface ought to be not difficult to learn, perceive, and recall, since one of the significant focuses for clients is to acknowledge the program $[11,12]$. The learning interface ought to be straightforward and simple to work by various age gatherings to guarantee better utilization of the application.

Hypothesis 1c: usability has a significant effect on user satisfaction with M-learning applications for children.

Portability: it is the ability to transfer an application from one environment to another, as well as the ability of the application to adapt to different mobile devices, with no further action configurations [15]. Besides, it is the ability of the application to be installed and uninstalled easily on different mobile devices [21].

Hypothesis 1d: portability has a significant effect on user satisfaction with M-learning applications for children.

Maintainability: it is the ability of the application to make adjustments that may include corrections, improvements, or adjustments to the program for changes in the environment, requirements, and functional specifications (the effort required for modification); the application must be designed about ease of maintenance [21].

Hypothesis 1e: maintainability has a significant effect on user satisfaction with M-learning applications for children.

3.2. Pedagogy. Pedagogically sound design for M-learning application development is a key factor for providing a pleasant and rich learning experience in a mobile environment [19]. Therefore, pedagogical factors influence user satisfaction with M-learning applications for children $[11,12,14-20]$.

Hypothesis 2: pedagogical factors have a significant effect on user satisfaction with M-learning applications for children.

The M-learning's pedagogical characteristics comprise the following subcharacteristics:

Educational activities: it is a learning theory that relies upon the student in learning circumstance and incorporates all learning practices, as well as instructing methodology that intends to initiate and amplify the student's part during learning through work and research. Therefore, it also relied on the student's confidence in getting data and acquiring abilities. Furthermore, learning theory it is not just center on retention and teaching, but also focuse on creating thinking and the capacity to take care of issues $[12,21]$.

Hypothesis 2a: educational activities have a significant effect on user satisfaction with M-learning applications for children.

Content quality: content quality must be valid, trustworthy, and accurate. In an M-learning environment, the content must consider the pedagogical aspects to generate efficient learning. It should be useful and appropriate for initial learning objectives, age, and level of the children [8]. It should also motivate the learner to plan educational goals in the M-learning environment in a correct, accurate, and clear manner consistent with the learning strategy in a way that serves the educational content provided to achieve the general and final objectives expected by the learner [22, 23].

Hypothesis $2 \mathrm{~b}$ : content quality has a significant effect on user satisfaction with M-learning applications for children.

Content and engagement: to get children's attention to the application, the content must be engaging. Effective content and participation in the mobile application are two measures that provide real insight into the success of the application [24, 25]. Negative content and low application sharing are a recipe for failure, while high engagement and retention are the opposite [19-26]. The success of the application can be determined through user engagement and activity, by using appropriate familiar content, language, and concepts [27]. 
Hypothesis 2c: content and engagement have a significant effect on user satisfaction with M-learning applications for children.

3.3. User Satisfaction. User satisfaction shows the user's response to the effective use of the information system $[11,21]$. The user becomes satisfied with the system when it meets his requirements and needs. One prerequisite for successful M-learning is that students feel satisfied with the application of learning as a sign of the quality of education [19]. High user satisfaction contributes to greater educational outcomes. Therefore, technical factors and pedagogical factors influence user satisfaction with M-learning applications for children $[16,20,28]$.

\section{Research Methodology}

The method used in this paper is based on a quantitative approach. The quantitative method provides advantages such as accurate, reliable, and fast data collection, a broader set of data analysis, elimination of bias, and tendency. Data for this paper were collected through the questionnaire because the questionnaire is the most common and practical way to collect data in quantitative studies. In our research, the sample was children who cannot understand how to fill the questionnaire and need more explanation about the questionnaire items. For this reason, we requested from the parents to help their children and explain the questions to them and then fill the form based on their answers. In the survey questionnaire, we mentioned that all answers from respondents will be confidential and we will minimize any risks of breach of confidentiality as presented in Appendix B.

The survey was conducted in Amman, Jordan. The questionnaire way is used to collect data for this study in both English and Arabic because many of the participants have Arabic as their own mother tongue; it was necessary to translate the questionnaire to reduce misunderstanding and help participants understand the research topic. The items of the questionnaire were adopted from related studies $([13,29-31]$ and [32-38]) (see appendix A). The questionnaire uses Google Forms online and is delivered manually to the parents of the children. To verify the questionnaire, the researcher presented the tool to a committee composed of 4 faculty members at Al-Zaytoonah University with experience, expertise, and competence to measure the appropriateness of each element of the questionnaire in terms of language and formulate and achieve the goal. In line with their directives and proposals, the wording of some of their phrases was modified, and a few of them were added and deleted. The study community consists of parents of children in primary schools and preschools, between the ages of 3 and 12 years.

The data collected from the survey delivery included responses of 240 participants. 10 answers were rejected as they were incomplete. The statistical treatment of the data got by the researcher using the SPSS package was performed, and the data from 220 parents were analyzed. Therefore, the sample size in this paper suffices to represent the views of parents about the quality of learning applications for children as an exploratory study.

The demographic composition of the research was $52.7 \%$ females and $47.3 \%$ male. Given the age group, it was 3 to 5 $(31.8 \%), 6$ to $8(31.4 \%)$, and 9 to $12(36.8 \%)$ as shown in Table 2. About children mainly using their smart devices with the highest video viewing rate of $56.5 \%$, the gameplay rate is $45.7 \%$, followed by the educational gaming operator with $26 \%$, taking pictures and video with $17.9 \%$, and completing schoolwork increased by $16.6 \%$. As shown in Table 2, the number of hours spent by children on electronic devices in one day ranged from one to two hours, $32.3 \%$, while their use of these devices ranged from 2 to 3 hours (25.9\%) in the second place, from 3 to 4 hours $(19.1 \%)$ in the third position, from 5 to 6 hours $(8.2 \%)$ in the fourth position, and more than 6 hours $(4.1 \%)$ per day in the fifth position. For children using their smart devices, the results showed that the highest response was to watching videos (56.5\%), followed by playing games $(45.7 \%)$, educational games operator $(26 \%)$, and taking pictures and video (17.9\%). 16.6\% completed school work, as shown in Table 2.

\section{Data Analysis and Result}

The stability coefficient was calculated using the internal consistency method according to the Cronbach alpha equation. Table 3 shows the coherence coefficient according to the Cronbach alpha equation, as it becomes clear through it that stability of the test is high, which confirms that the test is of high stability. It can be used as a research measurement tool.

Multiple regression analysis was used for the effect of technical and pedagogical factors on user satisfaction with M-learning applications for children as shown in Table 4 . The table made it clear that the effect is significant on a level of significance of $a=0.05$ of the effect of technical and educational factors on user satisfaction with M-learning for children where the correlation coefficient $R$ was 0.293 and the coefficient of explanation for explanatory variance $R^{2}$ was 0.077 , that is, the technical and educational factors explained $7.7 \%$ of the variation that occurred on the user's satisfaction with the portable learning of children. The value of " $F$ " was 10.185 and .000 represented a statistical significance, and there was the effect of technical factors and pedagogical factors on the user satisfaction with M-learning applications for children.

Results of a simple regression analysis of the effect of technical and pedagogical on user satisfaction with M-learning applications for children are shown in Table 5.

Hypothesis 1: “Technical factors have a significant impact on user satisfaction with M-learning applications for children" is accepted.

Hypothesis 1.a: "The functionality has a great impact on the user satisfaction with M-learning applications for children" is accepted.

Hypothesis 1.b: “The performance has a great impact on the user satisfaction with M-learning applications for children" is accepted. 
TABLE 2: Results of the demographic questions.

\begin{tabular}{|c|c|c|c|}
\hline & Categories & Frequency & Percent \\
\hline \multirow{3}{*}{ Gender } & Male & 104 & 47.3 \\
\hline & Female & 116 & 52.7 \\
\hline & $3-5$ & 70 & 31.8 \\
\hline \multirow{2}{*}{ Age group } & $6-8$ & 69 & 31.4 \\
\hline & $9-12$ & 81 & 36.8 \\
\hline \multirow{6}{*}{ Time } & Less than 30 minutes & 23 & 10.5 \\
\hline & From 1 to 2 hours & 71 & 32.3 \\
\hline & From 2 to 3 hours & 57 & 25.9 \\
\hline & From 3 to 4 hours & 42 & 19.1 \\
\hline & From 5 to 6 hours & 18 & 8.2 \\
\hline & More than 6 hours & 9 & 4.1 \\
\hline \multirow{5}{*}{ Children mainly use their smart devices } & Do school work & 37 & 16.6 \\
\hline & Watch the videos & 126 & 56.5 \\
\hline & Playing games & 102 & 45.7 \\
\hline & Taking photos and videos & 40 & 17.9 \\
\hline & Educational game player & 58 & 26 \\
\hline
\end{tabular}

TABLE 3: The internal consistency coefficient of Cronbach alpha.

\begin{tabular}{lr}
\hline Variable & Internal consistency \\
\hline Technical factors & 0.801 \\
Pedagogical factors & 0.773 \\
User satisfaction & 0.620 \\
The questionnaire & 0.866 \\
\hline
\end{tabular}

TABLE 4: Multiple regression analysis of the effect of technical and pedagogical factors on user satisfaction with M-learning applications for children.

\begin{tabular}{lcccccc}
\hline Independent variable & Beta & $T$ & Sig $t$ & $R$ & $R^{2}$ & $F$ \\
\hline Technical factors & 0.211 & 2.646 & 0.009 & 0.293 & 0.077 & 10.185 \\
Pedagogical factors & 0.114 & 1.426 & 0.155 & & & 0.000 \\
\hline
\end{tabular}

TABLE 5: Results of a simple regression analysis of technical and pedagogical subhypotheses.

\begin{tabular}{|c|c|c|c|c|c|c|c|c|}
\hline \multirow[t]{2}{*}{ Hypothesis } & \multirow[t]{2}{*}{$R$} & \multirow[t]{2}{*}{$R^{2}$} & \multicolumn{2}{|c|}{$\begin{array}{l}\text { Unstandardized } \\
\text { coefficients }\end{array}$} & \multirow[t]{2}{*}{$t$} & \multirow[t]{2}{*}{$f$} & \multirow[t]{2}{*}{ Sig } & \multirow[t]{2}{*}{ Results } \\
\hline & & & $\mathrm{B}$ & Std. error & & & & \\
\hline Technical & 0.278 & 0.073 & 0.495 & 0.116 & 4.272 & 18.249 & 0.000 & Accepted \\
\hline Functionality & 0.231 & 0.049 & 0.258 & 0.074 & 8.806 & 12.285 & 0.000 & Accepted \\
\hline Performance & 0.162 & 0.022 & 0.177 & 0.073 & 2.424 & 5.878 & 0.016 & Accepted \\
\hline Usability & 0.150 & 0.018 & 0.194 & 0.087 & 2.241 & 5.024 & 0.026 & Accepted \\
\hline Portability & 0.225 & 0.046 & 0.212 & 0.062 & 3.414 & 11.657 & 0.001 & Accepted \\
\hline Maintainability & 0.320 & 0.099 & 0.351 & 0.070 & 4.993 & 24.933 & 0.000 & Accepted \\
\hline Pedagogical & 0.237 & 0.052 & 0.470 & 0.130 & 3.607 & 13.013 & 0.000 & Accepted \\
\hline Educational activities & .260 & 0.064 & 0.364 & 0.091 & 3.983 & 15.867 & 0.000 & Accepted \\
\hline Content quality & .099 & 0.005 & 0.134 & 0.091 & 1.471 & 2.163 & 0.143 & Accepted \\
\hline Content engagement & .235 & 0.051 & 0.268 & 0.075 & 3.577 & 12.793 & 0.000 & Accepted \\
\hline
\end{tabular}

Hypothesis 1c: "The usability has a great impact on the user satisfaction with M-learning applications for children" is accepted.

Hypothesis 1d: "The portability has a great impact on the user satisfaction with M-learning applications for children" is accepted.
Hypothesis 1e: “The maintainability has a great impact on the user satisfaction with M-learning applications for children" is accepted.

Hypothesis 2:" Pedagogical factors have a significant impact on user satisfaction with M-learning applications for children" is accepted. 
TABLE 6: Questionnaire items.

1. Technical factors

1.1. Efficiency and performance factor

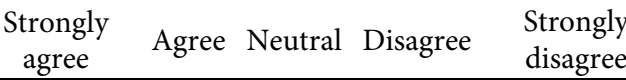
disagree

$1 \quad$ The child takes a short time to learn and understand mobile apps

Mobile learning applications respond quickly to complete a specific task

Mobile learning applications provide appropriate assistance

Mobile learning applications provide voice assistance

\subsection{Reliability factor}

In the event of application failures (such as disconnecting), the information entered into it must be preserved

$2 \quad$ Ease of handling errors in mobile learning applications

Mobile learning applications must resume work and recover lost data after failure

$4 \quad$ Multiple versions of the application help reduce errors

$$
\text { 1.3. Usability factor }
$$

The names of addresses, lists, and icons are compatible in mobile learning applications

2 Mobile learning application options are easy to understand and use

3 The child learns to use the mobile learning application easily without assistance

Child uses mobile learning apps without much effort

The mobile learning apps interface looks attractive to a child

\subsection{Functional factor}

Mobile learning apps contain a search engine, which facilitates the search for specific options

2 Mobile learning applications contain easy and relatively complete options and meet the requirements of the child

In mobile learning applications, the required tasks are performed and the result is as expected by the user

1.5. Maintainability factor

$1 \quad$ Easily diagnose errors in mobile learning applications

Easily correct errors and problems in mobile learning applications

If adjustments are made, the mobile learning apps will continue to work

Edits in portable learning apps are easily tested

1.6. Communication factor

Mobile learning applications contain specific tools to stimulate communication

with the child

2

Mobile learning applications provide some form of social interaction/ simultaneous play/or screen sharing

3 The application offers visual or auditory notes to children when they perform a certain task

\subsection{Advertisements factor}

1 Advertisements can completely distract the child's attention while using mobile learning applications

Advertisements indirectly encourage the child to track ads and exit the

2 application

$$
\text { 1.8. Portability factor }
$$

$1 \quad$ Easily install mobile learning applications on mobile devices

$2 \quad$ Mobile learning applications work regardless of device type 
TABle 6: Continued.

2. Pedagogical factors

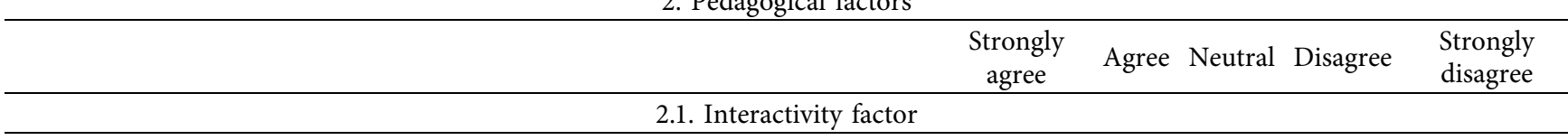

Child participates in mobile learning applications through activities that challenge the child

Mobile learning applications reduce kid's keyboard usage, which means avoiding typing as much as possible

3 The child is able to move freely and easily between different topics to choose the topic he wants

4

Child controls the transition between the elements and contents of the mobile learning application

5

The application allows the child to leave or return to mobile learning applications easily

6 The user-interface helps the child to quickly access the required information

7 Mobile learning applications to suit the capabilities of the targeted children

8 The interface should be appropriate to the nature of the educational missions to be learned

9

Displaying intense information on a single screen should be avoided in children's mobile learning applications

2.2. Educational activities factor

$1 \quad$ Mobile learning activities aim at the child's interaction

$2 \quad$ Mobile learning activities shift from simple to complex

3 Mobile learning activities must be provided in an attractive and linguistically accurate manner

4

Mobile learning activities reflect the child's surrounding and realistic environment

5 The goals of educational activities are beneficial to the child and develop the skills he applies to his life

$6 \quad$ Mobile learning activities are clear and accurate

7 The activities and educational materials used in the application must contain text, images, graphics, multimedia, games, sound, and others

\subsection{Content quality factor}

1 In a mobile learning application, the content provided must relate to specific educational goals

2 In a child's mobile learning application, the general characteristics of the age group must be taken into account

The child's mobile learning application takes into account the current and

3 previous knowledge, so that there is an integrated link between old and new information

4 In the mobile learning application for the child, we must take into account the 4 individual differences between the children in terms of diversity in the content

5 In a child's mobile learning application, the content should focus on building knowledge, not listing information

6 In a mobile learning application for a child, the content must be attractive, modern and linguistically correct

7 The educational content must conform to the standards of the quality of mobile learning applications

2.4. Encouragement content factor

1. The mobile learning app provides encouraging rewards for keeping children engaged

2 The content of the mobile learning application is satisfactory, attractive and suitable for children

The app provides useful and attractive educational activities for the child's attention

4 The concepts used are familiar and compatible with children's mental models 3. User satisfaction

The mobile learning application performs the tasks in the best possible way and with the least time to reach the expected result

2 The mobile learning application is effective in achieving the goals, accomplishing the mission and reaching the expected result

3 In general, I am satisfied with mobile learning application because they are clear and consistent for children

4 Be satisfied with mobile learning apps because they are attractive to children 
Hypothesis 2.a: “The educational activities have a great impact on the user satisfaction with M-learning applications for children" is accepted.

Hypothesis 2.b: "The content quality has a great impact on the user satisfaction with M-learning applications for children" is accepted.

Hypothesis 2c: "The content engagement has a great impact on the user satisfaction with M-learning applications for children" is accepted.

\section{Conclusion and Future Works}

This paper focused on proposing a quality model for M-learning applications for children. The model was created primarily from systematic references conducted in this field. It can be useful for researchers, designers, and other developers in designing M-learning applications for children aged between 3 and 12 years. Using the quantitative method, the researchers distributed the questionnaire to 220 parents of children in preschools and primary schools. The results of the sample show the influence of technical and educational factors on user satisfaction with children's mobile learning. The results of an analysis show acceptance of all subcharacteristics of the model which include functionality, performance, usability, portability, maintainability, educational activities, content quality, and content engagement; all subcharacteristics affect user satisfaction. The research presented interesting findings to the quality model for M-learning applications for children.

However, a single study cannot describe and solve the problem from all sides, so this paper has some limitations: The paper was conducted only in Amman, Jordan. The paper randomly selected 220 parents of children of different ages. The proposed model contains a specific set of quality characteristics, not all-inclusive. The results confirmed the impact of technical and pedagogical factors on user satisfaction with M-learning applications for children. The paper recommended the following: Benefiting from the results of the study when designing M-learning applications for children and enriching research in quality models for M-learning for children, especially in children learning. Educational institutions should plan to monitor, evaluate, and generalize the experience of the quality model for M-learning applications for children. One specific interesting avenue for future work would be to explore further into the antecedents to children satisfaction with M-learning application found in this study, namely, functionality, performance and efficiency, ease of use, portability, serviceability, educational activities, content quality, and content engagement. Another area of user-centric research in M-learning would be to determine the characteristics and behaviors of learners in various M-learning application adopter categories.

\section{Appendix}

\section{A. Questinnaire Items}

The questionnaire items are shown in Table 6.

\section{B. Survey Consent Paragraph}

You are being invited to participate in a research study titled: Propose a New Quality Model for M-learning Application In Light Of COVID-19. This study is being done by Ahmad Althunibat, Raneem Dawood, Mohammed Amin Almaiah and Feras Altarawneh from the Alzytoonah University of Jordan. You were selected to participate in this study because you are parent of students used mobile learning. The purpose of this research study is to suggest a quality model for M-learning applications for children. If you agree to take part in this study, you will be asked to complete the survey/questionnaire on the next page. It will take you approximately 10 minutes to complete. You may not directly benefit from this research; however, The authors hope that your participation in the study can be useful for researchers, designers, and other developers in designing M-learning applications for children between 3 and 12 years old. To the best of our ability your answers in this study will remain confidential. The authors will minimize any risks to breach of confidentiality.

\section{Data Availability}

The SPSS data used to support the findings of this study are available from the corresponding author upon request.

\section{Conflicts of Interest}

The authors declare that they have no conflicts of interest to report regarding this study.

\section{Acknowledgments}

This research was funded by Al-Zaytoonah University of Jordan (14/11/2020-2021).

\section{References}

[1] M. Alrasheedi and L. F. Capretz, "Determination of critical success factors affecting mobile learning: a meta-analysis approach," Turkish Online Journal of Educational Technology, vol. 14, no. 2, pp. 41-51, 2015.

[2] M. A. Almaiah, A. Al-Khasawneh, and A. Althunibat, "Exploring the critical challenges and factors influencing the E-learning system usage during the COVID-19 pandemic," Education and Information Technologies, vol. 25, no. 1, pp. 5261-5280, 2020.

[3] S. Papadakis and M. Kalogiannakis, "Mobile educational applications for children: what educators and parents need to know," International Journal of Mobile Learning and Organisation, vol. 11, no. 3, pp. 256-277, 2017.

[4] M. A. Almaiah and A. Al Mulhem, "Analysis of the essential factors affecting of intention to use of $\mathrm{m}$ learning applications: a comparison between universities adopters and non-adopters," Education and Information Technologies, vol. 24, no. 2, pp. 1433-1468, 2019. 
[5] S. Papadakis, M. Kalogiannakis, and N. Zaranis, "Designing and creating an educational app rubric for preschool teachers," Education and Information Technologies, vol. 22, no. 6, pp. 3147-3165, 2019.

[6] S. Nizam Ismail, S. Hamid, M. Ahmad, A. Alaboudi, and N. Jhanjhi, "Exploring students engagement towards the learning management system (lms) using learning analytics," Computer Systems Science and Engineering, vol. 37, no. 1, pp. 73-87, 2021.

[7] A. Althunibat, M. A. Almaiah, and F. Altarawneh, "Examining the factors influencing the mobile learning applications usage in higher education during the COVID-19 pandemic," Electronics, vol. 10, no. 21, p. 2676, 2021.

[8] M. A. Almaiah and O. A. Alismaiel, "Examination of factors influencing the use of m-learning system: an empirical study," Education and Information Technologies, vol. 24, no. 1, pp. 885-909, 2019.

[9] M. A. Almaiah, M. M. A. Jalil, and M. Man, "Empirical investigation to explore factors that achieve high quality of mobile learning system based on students' perspectives," Engineering science and technology, an international journal, vol. 19, no. 3, pp. 1314-1320, 2016.

[10] J. Qian, J. Cheng, Y. Zeng, and D. W. Tjondronegoro, “Design and implementation of museum educational content based on mobile augmented reality," Computer Systems Science and Engineering, vol. 36, no. 1, pp. 157-173, 2021.

[11] M. A. Almaiah, O. Almomani, A. Al-Khasawneh, and A. Althunibat, "Predicting the acceptance of mobile learning applications during COVID-19 using machine learning prediction algorithms," Emerging Technologies During the Era of COVID-19 Pandemic, vol. 348, pp. 319-332, 2021.

[12] N. Nordin, M. A. Embi, and M. M. Yunus, "M-learning framework for lifelong learning," Procedia - Social and Behavioral Sciences, vol. 7, no. 2, pp. 130-138, 2010.

[13] M. A. Almaiah, A. Al-Khasawneh, A. Althunibat, and O. Almomani, "Exploring the main determinants of mobile learning application usage during covid-19 pandemic in Jordanian universities," Emerging Technologies During the Era of COVID-19 Pandemic, vol. 348, pp. 275-290, 2021.

[14] S. A. Salloum, M. Al-Emran, K. Shaalan, and A. Tarhini, "Factors affecting the E-learning acceptance: a case study from UAE," Education and Information Technologies, vol. 24, no. 1, pp. 509-530, 2019.

[15] C. X. Navarro, A. I. Molina, M. A. Redondo, and R. JuárezRamírez, "Framework to evaluate m-learning systems: a technological and pedagogical approach," IEEE Revista Iberoamericana de Tecnologias del Aprendizaje, vol. 11, no. 1, pp. 33-40, 2018.

[16] M. Maqableh and M. Alia, "Evaluation online learning of undergraduate students under lockdown amidst COVID-19 Pandemic: the online learning experience and students' satisfaction," Children and Youth Services Review, vol. 128, Article ID 106160, 2021.

[17] W. Winarno, Y. Muhtadi, and M. A. Aldiya, "Application of learning management using non-test instrument to improve the quality of education," Aptisi Transactions on Management (ATM), vol. 3, no. 1, pp. 46-56, 2019.

[18] Y. Zhang, "The implementation of an English word learning system feedback system and smartphone app," Computer Systems Science and Engineering, vol. 35, no. 3, pp. 207-214, 2020.

[19] H. Jeong and Y. H. Kim, "A system software quality model using DeLone \& McLean model and ISO/IEC 9126,"
International Journal of Digital Content Technology and its Applications, vol. 6, no. 5, pp. 181-188, 2012.

[20] W. Rubens, B. Emans, T. Leinonen, A. G. Skarmeta, and R.-J. Simons, "Design of web-based collaborative learning environments. Translating the pedagogical learning principles to human computer interface," Computers \& Education, vol. 45, no. 3, pp. 276-294, 2005.

[21] M. Sarrab, M. Elbasir and S. Alnaeli, "Towards a quality model of technical aspects for m-learning services: an empirical investigation," Computers in Human Behavior, vol. 55, no. 1, pp. 100-112, 2012.

[22] S. Kioko, M. Kimwele, and L. Nderu, "A learnability model for children mobile applications," International Journal of Computer Applications Technology and Research, vol. 8, no. 5, pp. 182-195, 2019.

[23] M. Abdellatief, A. B. Sultan, M. A. Jabar, and R. Abdullah, “A technique for quality evaluation of e-learning from developers' perspective," American Journal of Economics and Business Administration, vol. 3, no. 1, pp. 157-164, 2011.

[24] M. Al-Emran, V. Mezhuyev, and A. Kamaludin, "Technology Acceptance Model in M-learning context: a systematic review," Computers \& Education, vol. 125, no. 1, pp. 389-412, 2012.

[25] M. A. Almaiah, "Acceptance and usage of a mobile information system services in University of Jordan," Education and Information Technologies, vol. 23, no. 5, pp. 1873-1895, 2018.

[26] G. Wenyuan, "Using smart phone to facilitate vocabulary m-learning and teaching in Chinese college," International Journal of Arts and Commerce, vol. 6, no. 4, pp. 41-36, 2017.

[27] U. Imtinan, v. Chang, and T. Issa, "Common M-learning characteristics-an analysis of M-learning models and frameworks," in Proceedings of the International Conference Mobile Learning 2013, pp. 3-11, IADIS Press, Portugal, 14 March 2013.

[28] A. Hussain, E. Mkpojiogu, and F. Hassan, "Dimensions and sub-dimensions for the evaluation of M-learning apps for children: a review," International Journal of Engineering \&Technology (IJET), vol. 7, no. 3, pp. 20-34, 2018.

[29] A. Althunibat, "Determining the factors influencing students" intention to use m-learning in Jordan higher education," Computers in Human Behavior, vol. 52, pp. 65-71, 2015.

[30] I. Almarashdeh, M. K. Alsmadi, G. Jaradat et al., "Looking inside and outside the system: examining the factors influencing distance learners satisfaction in learning management system," Journal of Computer Science, vol. 14, no. 4, pp. 453-465, 2018.

[31] M. Abduljawad, A. Ahmad, K. M. Jaber et al., "Evaluating and adopting E-learning systems in Al-zaytoonah university of Jordan," Int. J. Advance Soft Compu. Appl, vol. 12, no. 3, pp. 82-99, 2020.

[32] A. Althunibat, M. Binsawad, M. A. Almaiah et al., "Sustainable applications of smart-government services: a model to understand smart-government adoption," Sustainability, vol. 13, no. 6 , p. $3028,2021$.

[33] M. A. Almaiah and Y. Nasereddin, "Factors influencing the adoption of e-government services among Jordanian citizens," Electronic Government, an International Journal, vol. 16, no. 3, pp. 236-259, 2020.

[34] M. A. Almaiah and M. M. Alamri, "Proposing a new technical quality requirements for mobile learning applications," Journal of Theoretical and Applied Information Technology, vol. 96, no. 19, 2018. 
[35] S. S. Alghazi, A. Kamsin, M. A. Almaiah, S. Y. Wong, and L. Shuib, "For sustainable application of mobile learning: an extended UTAUT model to examine the effect of technical factors on the usage of mobile devices as a learning tool," Sustainability, vol. 13, no. 4, p. 1856, 2021 Jan.

[36] M. Al Amri and M. A. Almaiah, "Sustainability model for predicting smart education technology adoption based on student perspectives," International Journal of Advances in Soft Computing and Its Applications, vol. 13, no. 2, $2021 \mathrm{Jul} 1$.

[37] M. A. Almaiah, "Thematic analysis for classifying the main challenges and factors influencing the successful implementation of e-learning system using NVivo," International Journal of Advanced Trends in Computer Science and Engineering, vol. 9, no. 1, pp. 142-152, 2020.

[38] A. Al Mulhem and M. Almaiah, "A conceptual model to investigate the role of mobile game applications in education during the COVID-19 pandemic," Electronics, vol. 10, no. 17, p. 2106, 2021 Jan. 